\title{
Change in neonatal response to optimizing and non-optimizing sucking stimulation'
}

\author{
L. P. Lipsitt and Herbert Kaye \\ BROWN UNIVERSITY
}

\begin{abstract}
Abstraet
Three groups of human newborns were presented with 50 trials of intra-oral stimulation for 10-sec. durations while sucking rate was recorded. One received 10 blocks of five-trial alternations of rubber-nipple and rubbertube stimulation, one received 50 trials of tube alone, and another of nipple alone. The nipple elicited more sucking than the tube. In the alternation group, the nipple elicited an increasing amount of sucking over trials within blocks, while the tube elicited a decreasing amount, apparently due partly to a contrastphenomenon whereby the nipple became more effective in eliciting sucking through alternation with the less effective stimulus, and partly to perseveration, whereby sucking rate to the tube was highest immediately following the nipple trials.
\end{abstract}

\section{Problem}

Recently Lipsitt \& Kaye (1964) reported success in obtaining conditioning of sucking behavior to a tone, using sucking stimulation as reinforcement, in a group of human newborns. Papousek (1963) has reported conditioning of the head-turning response in neonates, using oral stimulation and feeding as reinforcing circumstances in a modified operant procedure. Prior to these recent studies, Marquis (1931) conducted an often overlooked conditioning study of neonates using oral reinforcement and feeding. These various studies indicate strongly that the behavior of human newborns is clearly modifiable on the basis of experiential circumstances, perhaps particularly those involving oral stimulation.

Gunther (1961) has recently made clinical observations of newborns having sucking and feeding difficulties; it is her contention that the size and shape of the intraoral stimulus are important determinants of the readiness and vigor with which sucking responses are elicited. The present study sought to document suckingrate differences obtained with an "optimizing" and "non-optimizing" stimulus using, respectively, an ordinary bottle nipple and a piece of straight 1/4-in laboratory tubing. Comparisons of rate differences between nipple and tube were made on both betweenand within-Ss data to determine whether experience with one would affect behavior to the other.

\footnotetext{
Method

The Ss were 30 ostensibly normal neonates born at the Providence Lying In Hospital ${ }_{9}^{2}$ and ranged in age from 48 to $96 \mathrm{hr}$. All Ss were tested once only between 8 and $9 \mathrm{a} . \mathrm{m}$. Of the $30 \mathrm{Ss}, 10$ participated in a procedure involving presentation of both the nipple and tube under an alternation procedure beginning with five trials of tube, followed by five trials of nipple, and so on; 10 Ss were administered a comparable
}

number of trials with the tube only; and 10 received the same number of trials with the nipple alone. All Ss received 50 trials of intra-oral stimulation, each lasting $10 \mathrm{sec}$., with an intertrial interval of approximately $30 \mathrm{sec}$. (deviations due only to differential times elapsing from the touch of the stimulus to the lips to the mouth opening, permitting entry of the stimulus). The tube was inserted approximately 1 in, the length of the nipple from tip to shield.

Trials were administered and responses recorded in the same way for all groups. After a 30-sec. interval, the experimenter touched or stroked the infant's lips with either the tube or nipple until the mouth opened. The stimulus was then inserted and the experimenter pushed a hand-button which simultaneously activated a polygraphic time-marker for a 10-sec. period and a small neon light near the infant's head, to signal the beginning and end of the period during which counts of sucking responses were made. Three observers were utilized for half of the data, and two for the other half. Interobserver counts of sucks per unit time are highly reliable, and the means of the observers were the basic data of the present study.

\section{Results and Diseussion}

Figure 1 shows the mean number of sucking responses made during the 50 trials by the three groups of $10 \mathrm{Ss}$. It can be seen that the nipple produces about twice as many sucking responses as the tube. The within-S

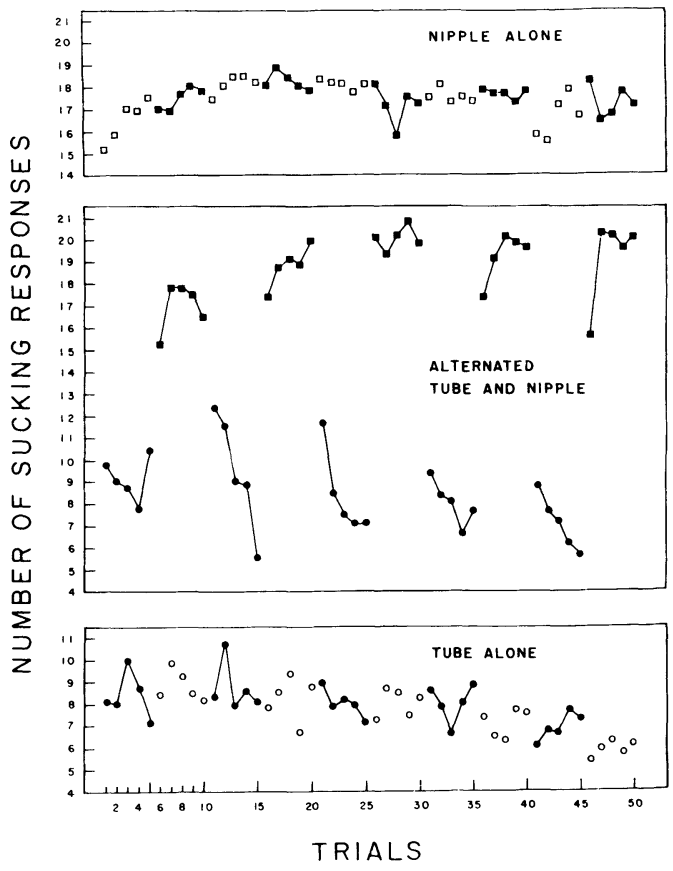

Fig. 1. Mean number of sucking responses on each of $5010-\mathrm{sec}$. trials made by three groups of $10 \mathrm{Ss}$. Responses on nipple-presentation trials are represented by circles. The dark squares and circles for the Nipple-Alone and Tube-Alone groups are the pertinent control trials for effects of alternation in the Tube-Nipple group. 
analysis comparing nipple and tube sucking for the alternated Ss yields a highly reliable effect $(t=10.45$; $\mathrm{df}=9 ; \mathrm{p}<.001$ ). A similar significant result is obtained for the comparison between the Tube-Alone and NippleAlone groups $(t=7.38 ; d f=19 ; p<.001)$. More pertinent to our present purpose, however, is the fact that within five-trial blocks for the Tube-Nipple group, there is an apparent effect of response to the previous stimulus administered, such that response to blocks of nipple presentation starts with a relatively low rate and goes up on ensuing trials, while response to the tube starts relatively high and decreases on subsequent trials. No such consistent effect is apparent on the pertinent comparison trials of the Tube-Alone and Nipple-Alone groups. This is seen more strikingly in Fig. 2, wherein the first 10 trials of all Ss are disregarded, and the last four blocks of tube and nipple presentation for the Tube-Nipple group are in Fig. 2, wherein the first 10 trials of all Ss are disregarded, and the last four blocks of tube and nipple presentation for the Tube-Nipple group are superimposed and plotted against the appropriate control trials of the Tube-Alone and Nipple-Alone groups. Nipple-responding and tube-responding in the alternating group over the five-trial blocks show inverse trends, and there is essentially no change in response rate over the comparable five-trial blocks in the Tube-Alone and

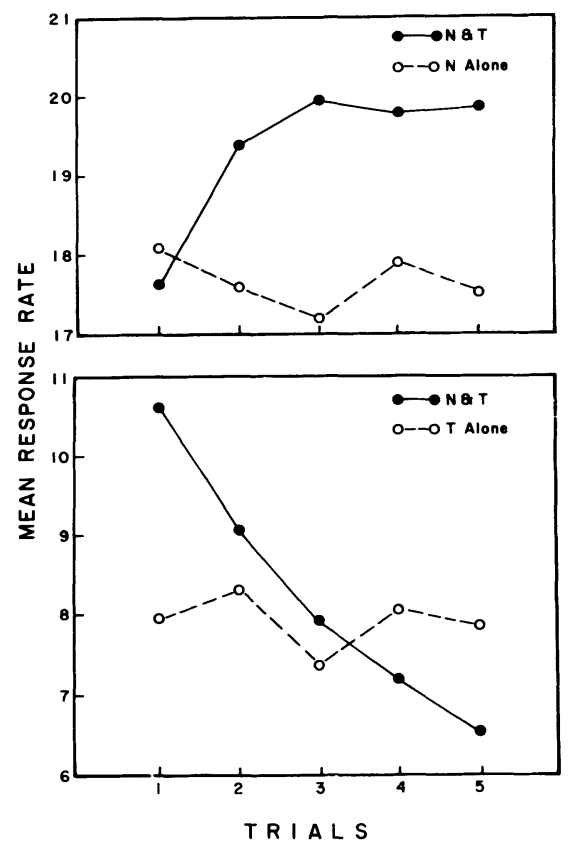

Fig. 2. Mean sucking rates for each of the three groups, eliminating the first two blocks (Trials 1-10) for all Ss. The upper graph compares sucking rate to the nipple of the Tube-Nipple and NippleAlone groups; the bottom graph compares rate to the tube of the Tube-Nipple and Tube-Alone groups. Four blocks of five trials are superimposed to produce these composite trends; Trial 1 for Tube-Alone, for instance, shows the averaged response of $10 \mathrm{Ss}$ in the Tube-Alone group for the first trial over four blocks.
Nipple-Alone groups. Non-parametric Friedman analyses of variance were used, confirming that both alternation-group trends (change in response to the nipple and tube respectively) are reliable $\left(x^{2}=9.28\right.$ and 18.16; $\mathrm{p}<.05$ and .001), while tests of similar effects in the Nipple-Alone and Tube-Alone conditions are not.

Although the Tube-Nipple and Nipple-Alone groups did not differ in sucking rate to nipple in the beginning of the five-trial blocks, there was a reliable difference in rate between the two groups at Trial 5 (KruskalWallis test, $\left.x^{2}=4.48 ; \mathrm{df}=1 ; \mathrm{p}<.05\right)$. It appears, then, that the Tube-Nipple group rose in response-rate to the nipple to a level greater than the "normative" level represented by the Nipple-Alone group. Such an effect is an apparent contrast phenomenon, whereby the nipple has become a stronger elicitor of response (more pleasurable?) through association with an alternative and less effective (tube) stimulus. While this same phenomenon is apparent in the comparison of the TubeNipple and the Tube-Alone groups with respect to tubesucking, the differences between groups at neither Trial 1 nor Trial 5 were reliable. However, since there was a reliable downward trend in tube-sucking for the TubeNipple group, it appears that both perseverational and contrast effects must have been involved, the former producing a higher response-rate early in blocks and the latter a lower rate later in blocks. The perseverative phenomenon could be observed qualitatively in the course of the study; when five nipple trials had been concluded for Ss in the alternation group, the next trial with the tube often elicited vigorous "nipple-like" sucking at the beginning of the 10-sec. period and was followed by a "surprise" reaction wherein sucking stopped abruptly and the infant proceded to explore the tube at a slower rate.

The present results clearly indicate that the nature of an intra-oral stimulus determines the frequency with which neonates suck, and that the sucking response to an oral stimulus is affected by other oral stimuli with which the infant has experience. Further study will be necessary to determine what the parameters of "optimizing" and "non-optimizing" oral stimuli are. It appears likely that both contour and texture would be pertinent.

\section{Relerences}

GUNTHER, M. Infant behavior at the breast. In B. Foss (Ed.), Determinants of infant behavior. London: Methuen \& Co., 1961. Pp. 37-44.

LIPSITT, L. P., \& KAYE, H. Conditioned sucking in the human newborn. Psychon. Sci., 1964, 1, 29-30.

MARQUIS, D. P. Can conditioned responses be established in the newborn infant? J. genet. Psychol., 1931, 39, 479-492.

PAPOUSEK, H. Conditioned head rotation reflexes in infants in the first month of life. Acta Pediatr., 1961, 50, 565-576.

\section{Notes}

1. This study was supported by a PHS research grant (NB 04268) to the senior author. We are indebted to Robert A. Hinde for interpretive suggestions.

2. We thank the staff of the Providence Lying In Hospital, and particularly Superintendent Harmon P. B. Jordan, Jr., for their encouragement and support. 